\title{
Utilization of Cenosphere in Manufacturing of Fly Ash Brick
}

\author{
R. Premkumar ${ }^{1, a^{*}}$, Ramesh Babu Chokkalingam ${ }^{1}$, B. Subha ${ }^{1}$, S. Pattu Sandhiya ${ }^{1}$ \\ ${ }^{1}$ School of Environmental and Construction Technology, Department of Civil Engineering, \\ Kalasalingam Academy of Research and Education, Krishnankoil, Tamil Nadu, India
}

aprem.ce@gmail.com

* corresponding author

\section{Keywords: Cenosphere, Low Density, Compressive Strength, Water Absorption}

\begin{abstract}
Our project was built with cenosphere material and low-density brick. The cenosphere bricks may be lighter and stronger than traditional fly ash bricks. Cement is used to replace the cenosphere in fly ash bricks in the following proportions: $230 \mathrm{~mm} \times 100 \mathrm{~mm} \times 75 \mathrm{~mm}$ sample size for blend percentage of cenosphere, fly ash, and quarry dust. The results show how compressive strength and water absorption vary with curing age for mixed proportions of the materials mentioned previously. Then we can use the $230 \mathrm{~mm} \times 100 \mathrm{~mm} \times 75 \mathrm{~mm}$ specimen size to cast bricks with various mix proportions of cenosphere, fly ash, and quarry dust. The weight, compressive strength, and water absorption of the cenosphere with various proportions of fly ash bricks were then compared. Via comprehensive laboratory work, this investigation is primarily based on optimizing the compressive strength of newly formed bricks thus minimizing weight density and water absorption. A definitive goal of undertaking this point as project work is to recognize factors influencing the different properties of bricks.
\end{abstract}

\section{Introduction}

The recognition of factors affecting the different properties of bricks is a clear aim of pursuing this point as project work. Ordinary bricks are made from clay and fired at high temperatures in a kiln, or from normal Portland cement (OPC) concrete. The high-temperature kiln firing not only consumes a lot of energy but also emits a lot of greenhouse gases. Cenospheres are void, unfilled, capable, microscopic rounded particles, composing of silica and alumina as extensive elements loaded with air or gases. Cenospheres are the decision of agitation of shattered coal at high temperature in a thermal power plant. Cenospheres are weightless dormant and empty particles, which are silicon dioxide, aluminum oxide, and iron oxide. The capacity of these particles is beginning in the range of 1 to $500 \mu$. They acquire reduce density due to blank and greater strength with, around 300psi as moderate compressive strength. These are the outgrowth in the form of fly-ash of coal-burning power plants. In the process of burning coal in thermal power plants, the fly-ash is rescued as a waste product consists of ceramic particles of alumina and silica. When burning coal has appeared at $1500^{\circ}$ to $1750^{\circ} \mathrm{C}$ temperatures, these cenosphere particles are composed, through hard physical and chemical transformation. These particles are utilizing by assorted industries in modern days like paints, plastics, ceramics, etc. But their production rate is much larger than its utilization rate. On the other side, fly-ash as well as cenospheres both are air pollutants, whatever element so many adverse impacts on human life. On the support of researches attended on cenospheres, it is realized that cenosphere particles are likewise used in construction industries.

Asad Hanif, Pavithra Parthasararhy (2017) Thermal insulating complex helps to lower total power consumption in a building by inventing a barrier between external and internal environment. This study proposes to produce a weightless cement-based composite for thermal 
isolating application [1]. Cement is moderately replaced with Silica fume and fly ash cenosphere and used as the weightless filler. Aerogel is used to recover thermal insulating behavior. The concrete mix specimen is also approved for the most temperature difference between the outer face and inner surface. The difference in temperature up to $16.78^{\circ} \mathrm{C}$ is accomplished which designated the thermal barrier of the building. The micro structural analysis determined the skillful bonding of fly ash cenospheres and aerogel in a cementitious system.

A. Hanif, (2017), in their preparatory study the effects of various weightless functional abound materials on the properties of cement concrete are checked [2]. They include fly ash cenospheres and glass micro-spheres in various ratios. The refined compounds are proved for compressive, flexure, and tensile strength [3]. The outcome determined that one and other cenospheres and glass micro-sphere are excellent abound materials for the strong weightless compound. They can be occupied for structural goals where higher mechanical strength is appropriate [4]. For the fiber-reinforced compound to effectively apply the tensile properties of fibers, fly ash cenospheres and glass micro-spheres are convenient [5]. Increased porosity is associated with a higher weight fraction of the abundant in composition, which could be the final step in improving their strength [6]. To determine the best mix configuration for achieving maximum compressive strength, water absorption, and weight bricks with low density and lightweight that can be handled easily.

\section{Materials}

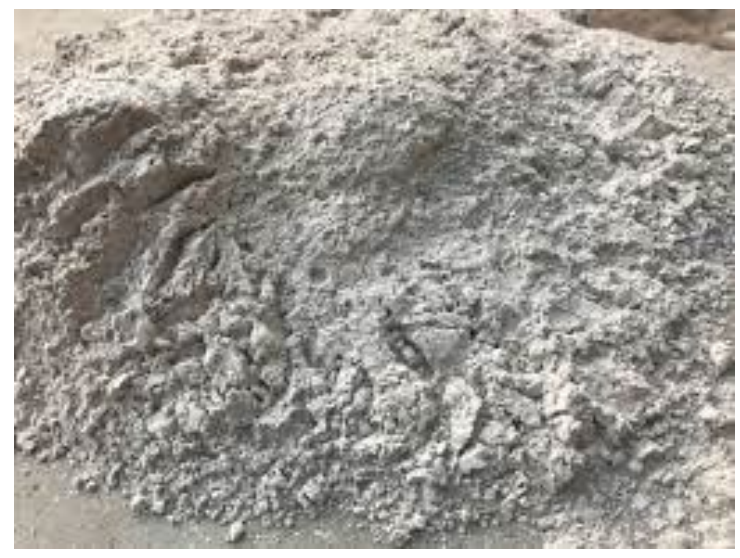

Figure 1.Cenosphere

Table 1.Cenosphere properties

\begin{tabular}{ccc}
\hline S.No & Property & Cenosphere \\
\hline 1 & Specific Gravity & 0.87 \\
2 & Blaine surface Area $\left(\mathrm{m}^{2} / \mathrm{Kg}\right)$ & 310 \\
3 & Particle Mean Dia & $<100$ \\
4 & Loss of ignition & $1.20 \%$ \\
\hline
\end{tabular}

\section{Cenosphere}

Figure 1 shows cenosphere is a lightweight, latent, hollow sphere built mainly of alumina, silica and loaded with inert gas or air, mostly combined as a derivative of coal burning at thermal power 
plants and properties as shown in table 1. It creates them enormous useful in a collection of products, prominently fillers. Now a day's Cenospheres are used as fillers in concrete to create low-density concrete. Newly, some manufacturers have started filling metals and polymers with cenospheres to produce lightweight composite mechanisms with high strength than other types of foam components.

\section{Fly ash}

Fly ash is a result of coal burning in nuclear energy production and comprises essentially $\mathrm{SiO}_{2}$, $\mathrm{Al}_{2} \mathrm{O}_{3}, \mathrm{Fe}_{2} \mathrm{O}_{3}, \mathrm{CaO}$, and some defilement. As pozzolanic materials are joined, calcium hydroxide $\mathrm{Ca}(\mathrm{OH})_{2}$ is converted to optional calcium silicate hydrate $(\mathrm{C}-\mathrm{S}-\mathrm{H})$ gel, resulting in the transformation of more pores into better pores due to the pozzolanic reaction of the mineral admixtures. The utilization of mineral admixtures positively affects the idea of cement by restricting the $\mathrm{Ca}(\mathrm{OH})_{2}$. A practical choice for mass use of fly ash can be in the creation of blocks containing fly ash as a more added substance. Because of the low calcium content of the fly debris used in this study, its behavior resembles that of a pozzolanic admixture in the block. In block, it responds with obviously consolidated lime to shape the response compounds.

Table 2.Quarry dust properties

\begin{tabular}{ccc}
\hline S.No & Property & Quarry Dust \\
\hline 1 & Specific Gravity & 2.62 \\
2 & Water Absorption & $0.5 \%$ \\
3 & Fineness Modulus & 3.324 \\
4 & Surface Texture & Rough \\
5 & Particle Shape & Angular \\
6 & Grading Zone & II (IS 2386 (Part I) 1963 \\
\hline
\end{tabular}

Table 3.Mix Proportions

\begin{tabular}{ccccc}
\hline Sample & OPC (\%) & Cenosphere (\%) & Fly ash (\%) & Quarry dust (\%) \\
\hline B0 & 10 & 0 & 60 & 30 \\
B1 & 10 & 10 & 50 & 30 \\
B2 & 10 & 20 & 40 & 30 \\
B3 & 10 & 30 & 30 & 30 \\
B4 & 10 & 40 & 20 & 30 \\
B5 & 10 & 50 & 10 & 30 \\
B6 & 10 & 60 & 0 & 30 \\
\hline
\end{tabular}




\section{Quarry dust}

It is sediment appropriated from a stone quarry. Because of the huge expense of travels from normal sources barely conceivable normal sand is high. Furthermore, natural problems of immense scope are exacerbated by the scarcity of these resources. The use of river sand in construction is becoming less appealing; a repurposed or reclamation product for the solid sector should be created. Some people have started orchestrating difficult issues for the sake of chance, expense, and environmental impact. Quarry rock dust is commonly used as a surface completing material and for installing empty squares and weightless cement pre-assembled Elements on interstates with a wide scope. Following that, fine particles with a diameter of less than $4.75 \mathrm{~mm}$ are used in this study, and their properties are mentioned in table 2. First Arriving blend level of cenosphere blocks of OPC(10\%), Cenosphere (60\%), and Quarry dust (30\%). Standard block sizes of $230 \mathrm{~mm} \times 100 \mathrm{~mm} \times 75 \mathrm{~mm}$ are utilized to project the blocks.

\section{Experimental Investigation}

The normal hand form is utilized to project the blocks along with the essential size of $230 \mathrm{~mm} \mathrm{x}$ $100 \mathrm{~mm} \times 75 \mathrm{~mm}$ as shown in figure 2 . They were projected to provide for the essential technique with various blend proportions showed up in table 3. The proper limit of Cenosphere, Cement, and Quarry dust is resolved as of now, given that the fixing blended impeccably. At that point dependent on the consistency water was added. At that point, the wet block was kept underneath air relieving for 24 hours, and afterward, blocks were water restored for a term of 7, 28day. Being each extent 12 quantities of blocks are projecting, in that 6 blocks are utilized to finish the compressive strength of block in $\mathrm{N} / \mathrm{mm}^{2}$ at 7days, 28days curing time, and 6 blocks are utilized to decide the water ingestion and Efflorescence test.
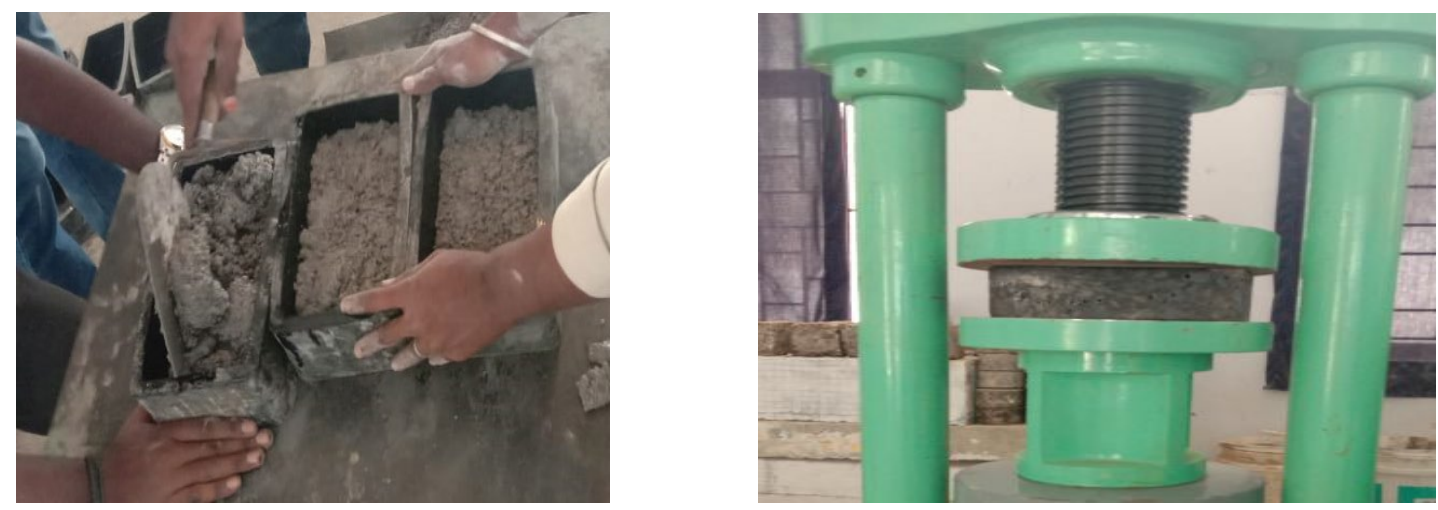

Figure 2. Casting and Testing of Bricks 


\section{Results and Discussion}

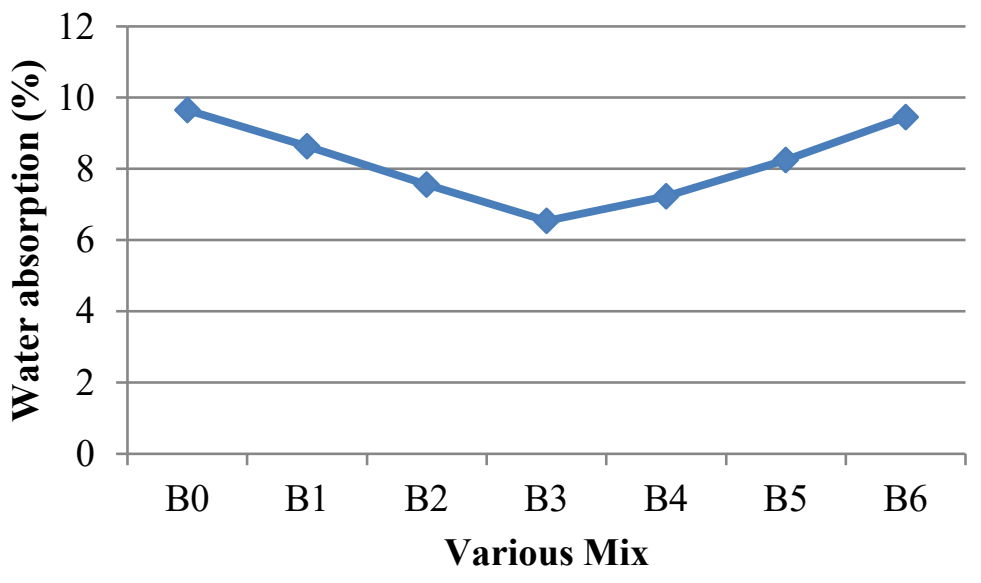

Figure 3. Various mix to Water absorption

\section{Water Absorption}

It is necessary to determine the amount of water absorption for new materials such as quarry dust and cenosphere, as it is a key factor in other tests and the production of bricks. It's a straightforward but important test for determining raw material water absorption up to saturation. Water absorption test: In this test, the collected materials were immersed in water for 24 hours and then dried in a laboratory oven at $1005^{\circ} \mathrm{C}$ for another 24 hours. Water was absorbed by the material in figure 3 to reflect the difference in weight compared to the original weight.

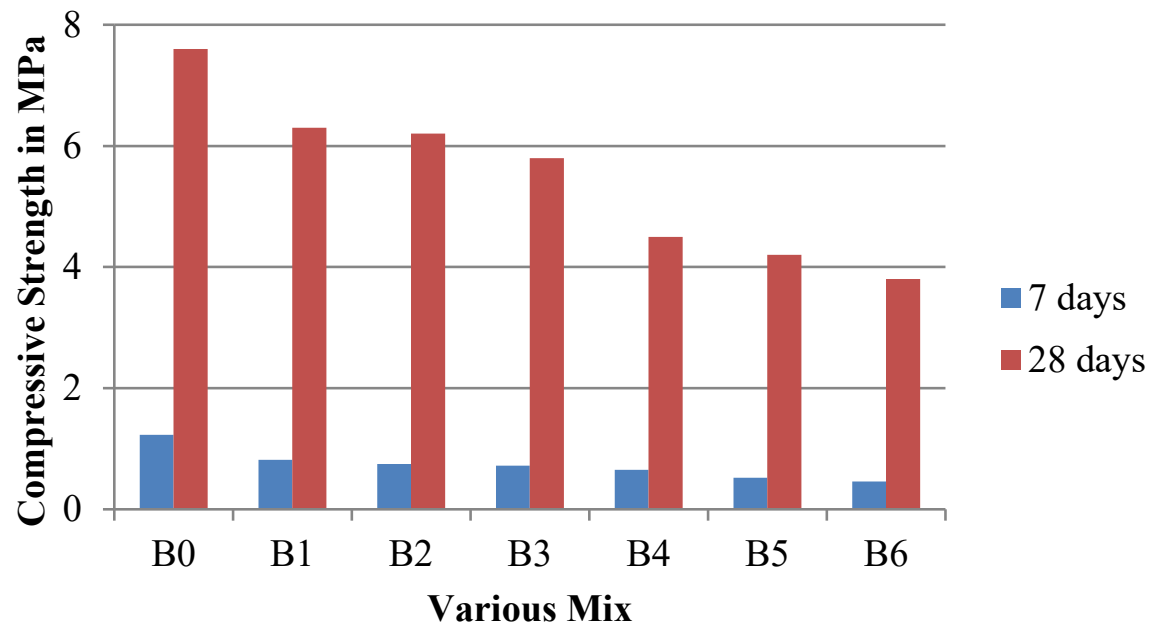

Figure 4: Represents the Compressive strength of the Brick sample

\section{Compressive Strength}

The compressive test was carried out on an automated Compression Testing Machine (CTM) with a capacity of $2000 \mathrm{kN}$, with a constant proceeding load of $0.6 \mathrm{kN} / \mathrm{sec}$. The proportion of ultimate failure load to the region of sample horizontal to the direction of load application was used to measure compressive strength $(\mathrm{MPa})$. Figure 4 indicates a higher reduction in strength as cenospheres substitute fly ash compared to standard fly ash bricks as the percentage of cenospheres increases. Compressive intensity is indirectly associated with the cenosphere's ash, as seen in the graph. Higher cenospheres are also associated with lower compressive strength. 


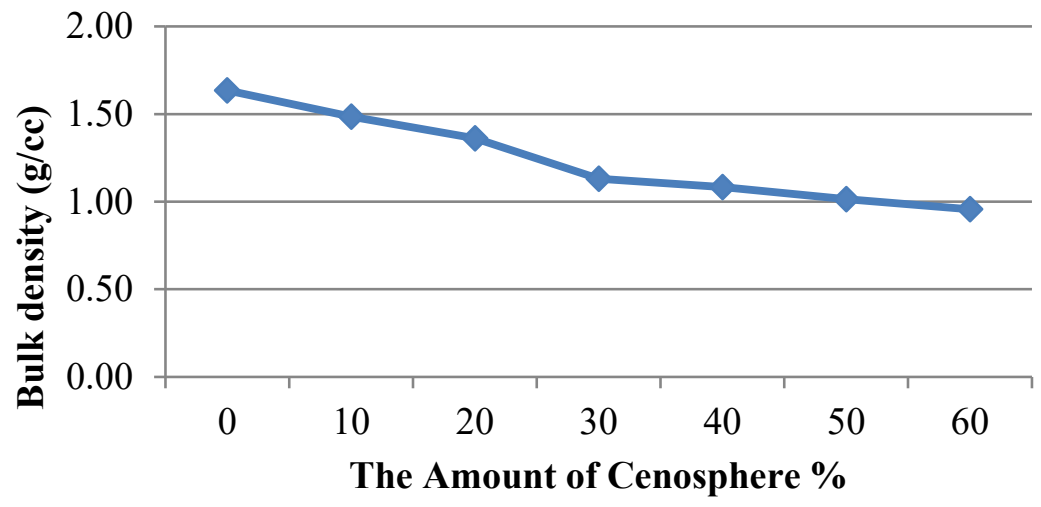

Figure 5: Represents the Bulk density of the Brick sample

\section{Bulk Density}

The bulk density was determined by dividing the sample's dry weight by the unfired sample's direct volume measurement (length-height-width). At each age, at least three samples were checked, and the moderate values were defined as the sample's bulk density, as shown in figure 5

\section{Efflorescence}

Efflorescence is costly, ivory; as the water evaporates; powdery drops of water-soluble salts disappear from the exterior of bricks. The IS 3495 (Part 3):1992 guidelines were used to coordinate this exam. The sample was fixed in water with one end absorbed for this examination. This was then fixed in a warm $\left(20-30^{\circ} \mathrm{C}\right)$ and well-ventilated room until the sample absorbed all of the water and the excess water dispersed. The modification was covered with glass to avoid excessive evaporation. The same process was repeated after the water had fully evaporated. After the second evaporation, the results were registered. According to the IS code, efflorescence was classified as zero ( $0 \%$ ), mild (not more than $10 \%$ ), restricted (up to 50\%), strong (more than $50 \%$ ), and extreme (more than 50\%) based on the percentage of naked area covered with a thin deposit of salt as visually authorized (powdering \& flaking of the surface). At the age of 28 days, this procedure was carried out. The efflorescence results were both satisfying and encouraging. The bricks made in this study showed no flowering in the arrangement for any of the mixes.

\section{Relationship between density and compressive strength}

Figure 6 accord the density and compressive strength of the fly ash bricks as a behave of the cenosphere percentage. The figures demonstrate that as the extension of cenospheres increment, the compressive strength was declined. For this position of the test, the bricks are made beyond air entrainment. Even at the $10 \%$ matched of cenospheres, the compressive strength was raised $5 \mathrm{MPa}$, which is dual that recommended by ASTM basic for harsh weather bricks. It can also be leading that the density of the brick goes down with the extension of cenospheres in a precise mode within the test area. The extension cenospheres allow a lighter brick with adequate compressive strength. By calculate $10 \%$ cenospheres, the brick density decreased from 2.82 to $2.56 \mathrm{~g} / \mathrm{cc}$, almost, which is a $10 \%$ decrease in density. 


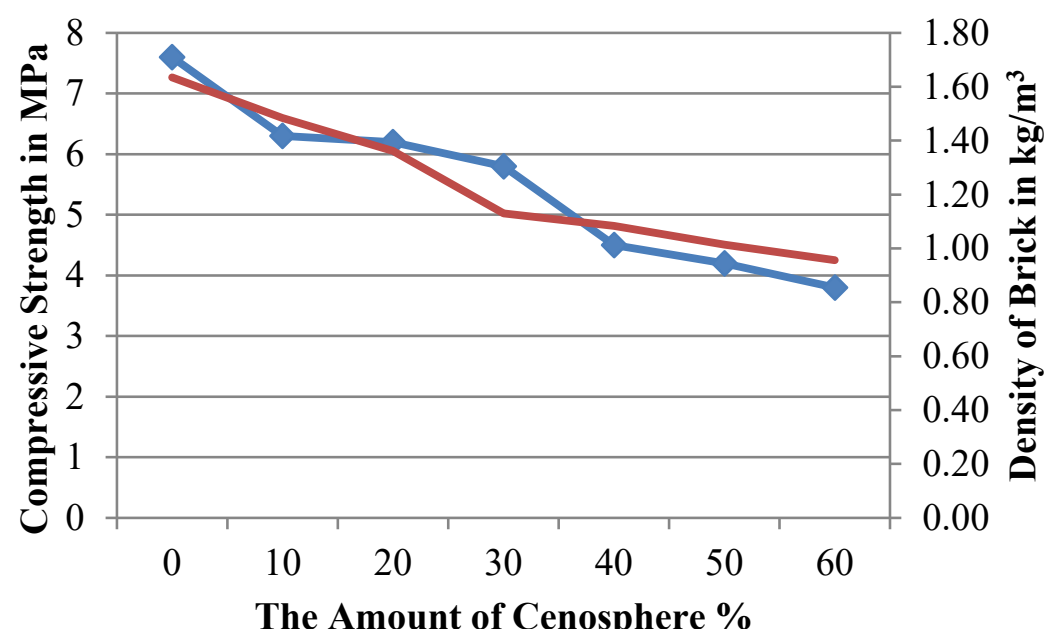

Figure 6: Graphical representation of Compressive Strength Vs bulk density

\section{Conclusion}

The following conclusions can be drawn from the findings of this study:

As expected, the expansion of cenospheres to fly ash blocks brings about a huge diminishing in brick density. For example, by adding $10 \%$ cenospheres, the brick density lessens by $10 \%$. This is useful for both cost and specialized reasons. The lower weight per block decreases delivery and work costs while simultaneously permitting more prominent structural plan adaptability. While the abatement in density relates to a diminishing in strength, at $60 \%$ cenospheres substitution, the compressive strength was as yet $3.56 \mathrm{MPa}$, which is well over the $3 \mathrm{MPa}$ needed by ASTM for extreme climate grouping

Also, the utilization of cenospheres in fly ash bricks is relied upon to deliver different advantages, for example, improved warm protecting properties. While the specialized part of adding cenospheres to fly ash block is promising, the current market estimation of cenospheres makes adding them unfeasible. Later on, as the cost of cenospheres diminishes, adding cenospheres may turn into a feasible alternative for creating quality fly ash bricks

\section{References}

[1] A. Hanif et al., "Properties Improvement of Fly Ash Cenosphere Modified Cement Pastes using Nano Silica," Cement and Concrete Composites, vol. 81, pp. 35-48, Elsevier Ltd, Aug 2017. https://doi.org/10.1016/j.cemconcomp.2017.04.008

[2] A. Hanif, Z. Lu, and Z. Li, "Utilization of fly ash cenosphere as lightweight filler in cement-based composites-a review,"Construction and Building Materials, vol. 144, pp. 373-384, 2017. https://doi.org/10.1016/j.cemconcomp.2017.04.008

[3] Sumathi, A., and Rajamohan K. S. (2014). "Compressive strength of fly ash brick with the addition of lime, gypsum, and quarry dust." International Journal of ChemTech Research, Vol. 7, No. 1, pp. 28-36

[4] Sutcu, M., Alptekin, H., Erdogmus, E., Yusuf, E., and Gencel, O. (2015). "Characteristics of fired clay bricks with waste marble powder addition as building materials." Construction and Building Materials, Vol. 82, pp.1-8. https://doi.org/10.1016/j.conbuildmat.2015.02.055 
[5] Wang, J., Zhang, M., Li, W., Chia, k., and, Liew, R. (2012). "Stability of cenospheres in lightweight cement composites in terms of alkali-silica reaction". Cement and Concrete Research, 42, 721-727. https://doi.org/10.1016/j.cemconres.2012.02.010

[6] Pahroraji, M., Saman, H. M., Rahmat, M. N., and Kamaruddin, K. (2013). "Compressive strength and density of unfired lightweight coal ash brick." International Civil and Infrastructure Engineering Conference, Kuching, Malaysia, pp. 22-24.

[7] IS: 3495 (Part 1): 1992 - Method of tests of burnt clay building bricks., Part 1- Determination of Compressive Strength

[8] IS: 3495 (Part 2): 1992 - Method of tests of burnt clay building bricks., Part 2- Determination of Water Absorption. 